\title{
HORASAN HARCINDA YUMURTA AKI KULLANIMININ INCELENMESI
}

\author{
İsmail Kılıç ${ }^{1 *}$ \\ Kırklareli Üniversitesi Mühendislik Fakültesi İnşaat Mühendsiliği Bölümü, Kırklareli, Türkiye
}

\begin{abstract}
Öz
$\mathrm{Bu}$ çalışmada, tarihi eserlerimizde yaygın olarak kullanılan horasan harcı üzerine araştırma yapılmıştır. Horasan harcı üretiminde, doğal hidrolik kireç, standart kum ve tuğla kırı̆̆ kullanılmıştır. Horasan harcında çeşitli katkılar kullanıldı ̆̆ bilinmektedir. Bu katkılardan bir tanesi de yumurta akıdır. Çalışmada, bir tanesi katkısız beş tanesi katkılı olmak üzere altı farklı horasan harcı karışımı üretilmiştir. Yumurta akı, karışımlarda \%5, \%10, \%15, \%20 ve \%25 oranlarında kullanılmıştır. Yumurta akı, kireç ağırlığının yüzdesi miktarında ilave olarak karışımlarda kullanılmıştır. Harç kalıbı kullanılarak 40mm x 40mm x160mm boyutlarında prizmatik horasan harcı örnekleri üretilmiştir. Taze harçlar üzerinde kıvam tayini deneyi, 28 günlük prizmatik harç örnekleri üzerinde ise birim hacim ağırlık, ultrases geçiş hızı, eğilme dayanımı ve basınç dayanımı deneyleri yapılmıştır. Deneyler sonucu elde edilen verilere dayalı olarak yumurta akının horasan harcı üzerindeki etkileri belirlenmiştir.
\end{abstract}

Anahtar Kelimeler: Hidrolik kireç, Horasan harc1, Kireç harc1, Tuğla kırığı, Yumurta ak1

\section{INVESTIGATION OF EGG WHITE USAGE IN KHORASAN MORTAR}

\begin{abstract}
In this study, a research has been done on khorasan mortar, which is widely used in our historical artifacts. In the production of Khorasan mortar, natural hydraulic lime, standard sand and brick crush are used. It is known that various additives are used in khorasan mortar. One of these additives is egg whites. In the study, six different mixtures of khorasan mortar were produced, one without additives and five with additives. Egg whites were used at the rates of 5\%, 10\%, 15\%, 20\% and $25 \%$ in the mixtures. Egg whites were used in the blends in addition to the percentage of lime weight. By using a mortar mold, $40 \mathrm{~mm}$ x $40 \mathrm{~mm}$ x $160 \mathrm{~mm}$ size prismatic mortar mortar samples were produced. Determination of consistency test has been carried out on fresh mortars. Unit weight, ultrasound velocity, flexural strength and compressive strength tests were performed on 28-day-old prismatic mortar samples. Based on the data obtained as a result of the experiments, the effects of egg white on the khorasan mortar were determined.
\end{abstract}

Keywords: Hydraulic lime, Khorasan mortar, Lime mortar, Brick fracture, Egg white Sorumlu Yazar: İsmail KILIÇ, ismail.kilic@klu.edu.tr 


\section{Giriş}

Tarihi eserlere sahip çıkmak her bireyin sorumluluk alanına girmektedir. Onları korumak ve gelecek kuşaklara en iyi şekilde emanet etmek gerekir. Gerektiğinde bu eserler restore edilmelidir. Restorasyon aşamasında aslına uygun malzemelerin kullanılması çok önemlidir. Horasan harcı tarihi eserlerin restorasyonunda yaygın olarak kullanılan bir malzemedir. Bu nedenle özelliklerinin çok iyi bilinmesi gerekmektedir.

Horasan harcı Roma, Bizans, Selçuklu ve Osmanlı dönemlerinde kullanılmıştır. Horasan kelimesinin İran'ın Horasan bölgesinden geldiği bilinmektedir [1,2]. Horasan, kırılmış, ögütülmüş tuğla ve kiremit gibi pişmiş killere denilmektedir [3]. Horasan harcı ise tuğla kırı̆̆ı, kireç, su, çeşitli lifler ve katkılar kullanılarak hazırlanan, bağlayıcı ve taşıyıcı özelliğe sahip, harç veya sıva olarak kullanılan bir malzemedir [4-6]. Bu harçların geliştirilmesi için katkı olarak organik maddeler kullanılmaktadır [3,7-9].

Kireç içeren harç ve sıvalar, eski dönemlerden çimentonun bulunmasına kadar geçen sürede yapıların inşalarında yaygın olarak kullanılmıştır [10-12]. Kireç içeren harçlar, su kemerleri, sarnıç ve hamam gibi inşaatlarında değerlendirilmiştir. [13-17]. Roma, Bizans, Selçuklu dönemi harçları, bağlayıcı/agrega oranları ve içerikleri, fiziksel ve mekanik özellikleri açısından birbirine benzemektedir [18].

Horasan harçlarında kullanılan bağlayıcı/agrega oranı 1/1 ile 1/4 arasında değişmekle birlikte 1/2 ile 1/3 arasında oranlar önerilmektedir [16,19-21]. Tuğla kırı̆̆ı harcın mekanik dayanımını artırmaktadır. Harcın içindeki agrega yoğunluğu ve boyutu harçların kullanım amaçlarına göre değişmektedir. İri agregalar mekanik dayanımı sağladıkları için örgü harçlarında daha fazla kullanılmaktadır [22]. Horasan harcında kullanılan pişmiş kil tozlarındaki silikatlar, kirecin su ile reaksiyonu sonucunda oluşan kalsiyum hidroksit ile reaksiyona girerek, suda çözünmeyen ve harca dayanım kazandıran kalsiyum silikat hidrat jellerine dönüşürler [23,24].

Bu çalışmada, horasan harcında katkı olarak kullanılan yumurta akının, harcın fiziksel ve mekanik özelliklerine ne gibi etkilerinin olacağı araştırılmıştır. 
Araştırma

DOI: 10.34186/klujes.882789
Kıllç/Kırklareli University Journal of Engineering and Science 7-1(2021) 122-134

Geliş Tarihi:18.02.2021

\section{Materyal ve Metot}

Horasan harcı üretiminde, 0-4 mm aralığında tuğla kırığı, standart kum, hidrolik kireç, su ve yumurta akı kullanılmıştır. Standart kum, Trakya Çimento Fabrikasından temin edilmiştir. Harman tuğlası veya dolu tuğla diye de adlandırılan tuğlaların çeneli kırıcıda kırılmasıyla 0-4 mm aralığındaki tuğla kırığı elde edilmiştir. Bağlayıcı olarak Teknorep 550 doğal hidrolik kireç kullanılmıştır. Harç karışımında kullanılan yumurta akı, standart kum ve tuğla kırığına ait görseller Şekil 1'de verilmiştir. Tablo 1'de ise elek analizi sonucu belirlenen, kum ve tuğla kırığına ait granülometrik veri bulunmaktadır.
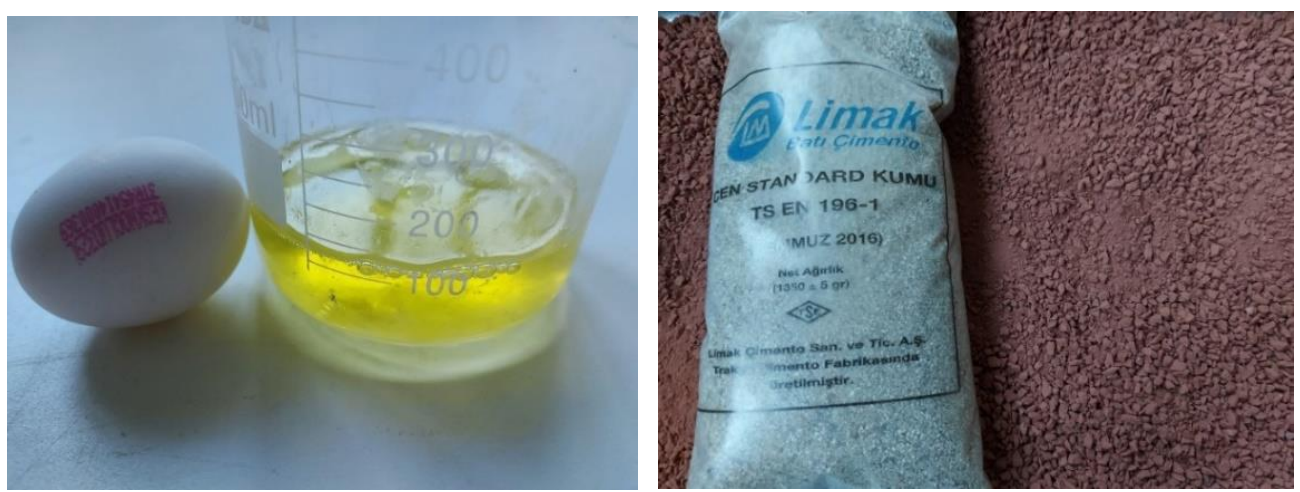

Şekil 1. Horasan harcı karışımında kullanılan yumurta akı, standart kum ve tuğla kırığ görüntüleri

Çalışmada, altı farklı horasan harcı üretilmiştir. Bunlardan bir tanesinde katkı olarak yumurta akı kullanılmamıştır. Bu harçtan üretilenler şahit örnek (M0) olarak değerlendirilmiştir. Diğer beş karışımda, \%5, \%10, \%15, \%20 ve \%25 oranlarında yumurta akı kullanılmıştır. Bunlar sırasıyla M1, M2, M3, M4 ve M5 olarak kodlanmışlardır. Yumurta akı, bağlayıcı olan kirecin ağırlıkça yüzdesi şeklinde ilave olarak karışıma katılmıştır.

Tablo 1. Kum ve tuğla kırığına ait granülometrik veriler

\begin{tabular}{|c|c|c|}
\hline \multirow{2}{*}{$\begin{array}{c}\text { Elek No } \\
(\mathbf{m m})\end{array}$} & \multicolumn{2}{|c|}{ Elekten Geçen (\%) } \\
\cline { 2 - 3 } & Kum & Tuğla Kırı̆̆ \\
\hline 4 & 100 & 100 \\
\hline 2 & 100 & 52,5 \\
\hline 1 & 64,5 & 33,7 \\
\hline 0,5 & 37,6 & 22,8 \\
\hline 0,25 & 21,5 & 9,2 \\
\hline
\end{tabular}


Araştırma

DOI: $10.34186 /$ klujes.882789
Kıllç/Kırklareli University Journal of Engineering and Science 7-1(2021) 122-134

Geliş Tarihi:18.02.2021

Horasan harcı üretiminde ağırlıkça karışım oranları su, kireç ve agrega (kum+tuğla kırığı) için sırasıyla 1, 1 ve 3 olarak tercih edilmiştir. Agreganın (kum+tuğla kırığı) kendi içerisindeki ağırlıç̧a oranı ise 1/4 kum ve 3/4 tuğla kırı̆̆ı olacak şekilde tasarlanmıştır. Üretilen horasan harçlarında kullanılan malzemelerin kendi içerisinde ağırlıkça oranları ve 1 adet harç kalıbı $\left(768 \mathrm{~cm}^{3}\right)$ için kullanılan malzeme miktarları Tablo 2'de verilmiştir. Katkı olarak kullanılan yumurta akı karışımlarda kireç ağırlığının ağırlıkça yüzdesi miktarında ilave olarak kullanılmıştır.

Tablo 2. Üretilen horasan harçlarında kullanılan malzemelerin kendi içerisinde ağırlıkça oranları ve karışımlardaki malzeme miktarları

\begin{tabular}{|c|c|c|c|c|c|c|c|c|c|}
\hline \multirow[t]{2}{*}{$\begin{array}{c}\text { Karışım } \\
\text { Kodu }\end{array}$} & \multirow{2}{*}{$\begin{array}{c}\text { Katk1 } \\
\text { Oranı } \\
(\%)\end{array}$} & \multicolumn{3}{|c|}{$\begin{array}{c}\text { Karışımdaki Malzemelerin } \\
\text { Ağırlıkça Oranları }\end{array}$} & \multicolumn{5}{|c|}{$\begin{array}{c}1 \text { Adet Harç Kalıbı İçin Kullanılan } \\
\text { Malzeme Miktarları (g) }\end{array}$} \\
\hline & & $\mathrm{Su}$ & Kireç & 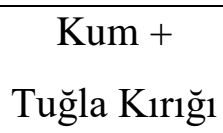 & $\begin{array}{l}\text { Yumurta } \\
\text { Ak1 }\end{array}$ & $\mathrm{Su}$ & Kireç & Kum & $\begin{array}{l}\text { Tuğla } \\
\text { Kırı̆̆ } 1\end{array}$ \\
\hline M0 & 0 & 1 & 1 & 3 & 0 & 400 & 400 & 300 & 900 \\
\hline M1 & 5 & 1 & 1 & 3 & 20 & 400 & 400 & 300 & 900 \\
\hline M2 & 10 & 1 & 1 & 3 & 40 & 400 & 400 & 300 & 900 \\
\hline M3 & 15 & 1 & 1 & 3 & 60 & 400 & 400 & 300 & 900 \\
\hline M4 & 20 & 1 & 1 & 3 & 80 & 400 & 400 & 300 & 900 \\
\hline M5 & 25 & 1 & 1 & 3 & 100 & 400 & 400 & 300 & 900 \\
\hline
\end{tabular}

Horasan harç örneklerinin kıvamı yayılma tablası ile TS EN 1015-3 [25], eğilme ve basınç dayanımları TS EN 1015-11 [26] standardına uygun olarak yapılmıştır. Ultrases geçiş süresi ise ASTM C 597 [27] standardına uygun olarak ve Pundit PL200 marka ultrasonik test cihaz1 kullanılarak ölçülmüştür.

Örnekler üretilirken, mikserde öncelikle kum, tuğla kırığı ve kireç karıştırılmış, sonra su ve yumurta akı ilave edilerek karışıma devam edilmiştir. Şekil 2'de görüldüğü gibi karıştırma işlemi bitince, taze horasan harcı üzerinde yayılma tablası kullanılarak kıvam deneyi yapılmıştır. 

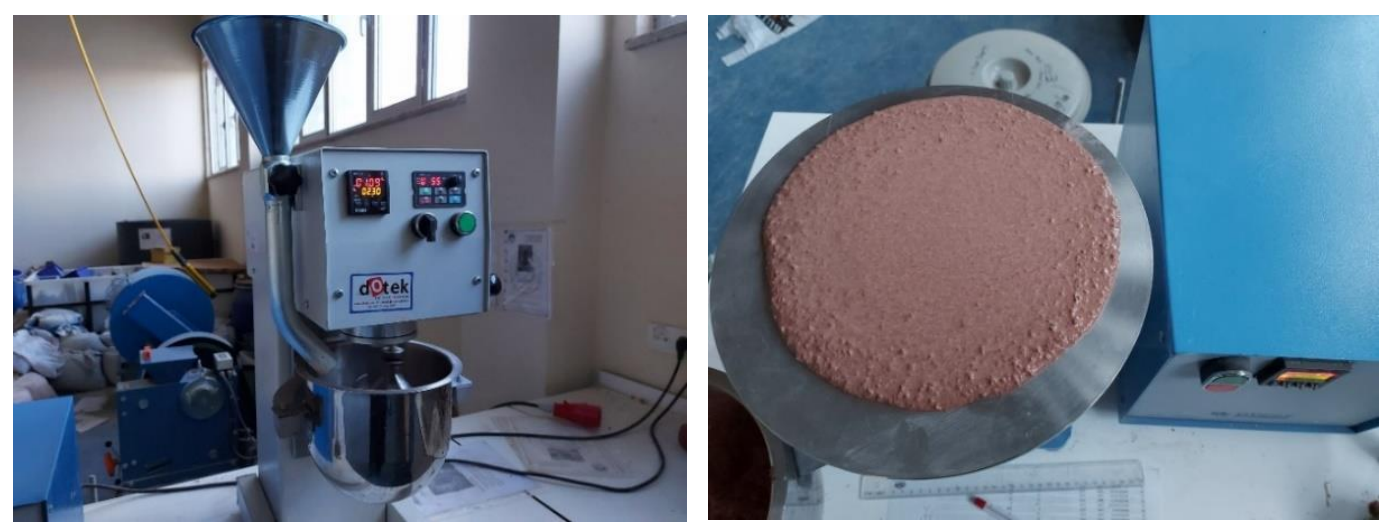

Şekil 2. Horasan harcının mikserde karıştırılma aşaması ve kıvam deneyi görüntüleri

Horasan harc1, $40 \mathrm{~mm} \times 40 \mathrm{~mm} \times 160 \mathrm{~mm}$ boyutlarında prizmatik örnekler olacak şekilde üretilmiştir. Her bir metal harç kalıbında üç adet, bu boyutlarda örnek üretmek mümkündür. Taze horasan harcı daha önce içerisi yağlanan metal kalıplara doldurulmuş ve sarsma tablası kullanılarak kalıba yerleşmesi sağlanmıştır. Her karışım kodu için birer adet olmak üzere toplam 6 adet metal kalıp kullanılmıştır. Her bir karışımdan üçer adet olmak üzere toplam 18 adet, $40 \mathrm{~mm} \times 40 \mathrm{~mm} \times$ 160mm boyutlarında prizmatik horasan harç örnekleri üretilmiştir. Harç örnekleri, yeterli dayanım kazanması için 48 saat bekletildikten sonra kalıptan çıkarılmıştır. 24 saat sonra kalıp tan çıkarmanın sakıncaları olabileceği düşünülmüştür. Kalıptan çıkarılan örnekler 28 günlük oluncaya kadar laboratuvar ortamında bekletilmiştir.

28 günlük harç örnekleri öncelikle tartılmış ve birim hacim ağırlıkları hesaplanmıştır. Şekil 3'de görülen örneklerin, ultrasonik test cihazı kullanılarak öncelikle ultrases geçiş süreleri ölçülmüş ve daha sonra eğilme dayanımları belirlenmiştir. Eğilme dayanım deneyinde ikiye ayrılan örneğin her iki tarafında kalan parçaları üzerinde basınç dayanım deneyi yapılmıştır. Her bir karışım koduna ait örnekler üzerinde yapılan ölçüm ve test sonuçlarının aritmetik ortalaması alınmış ve çalışma ile ilgili bulgularda kullanılmıştır. 


\section{Araştırma}

DOI: $10.34186 /$ klujes. 882789
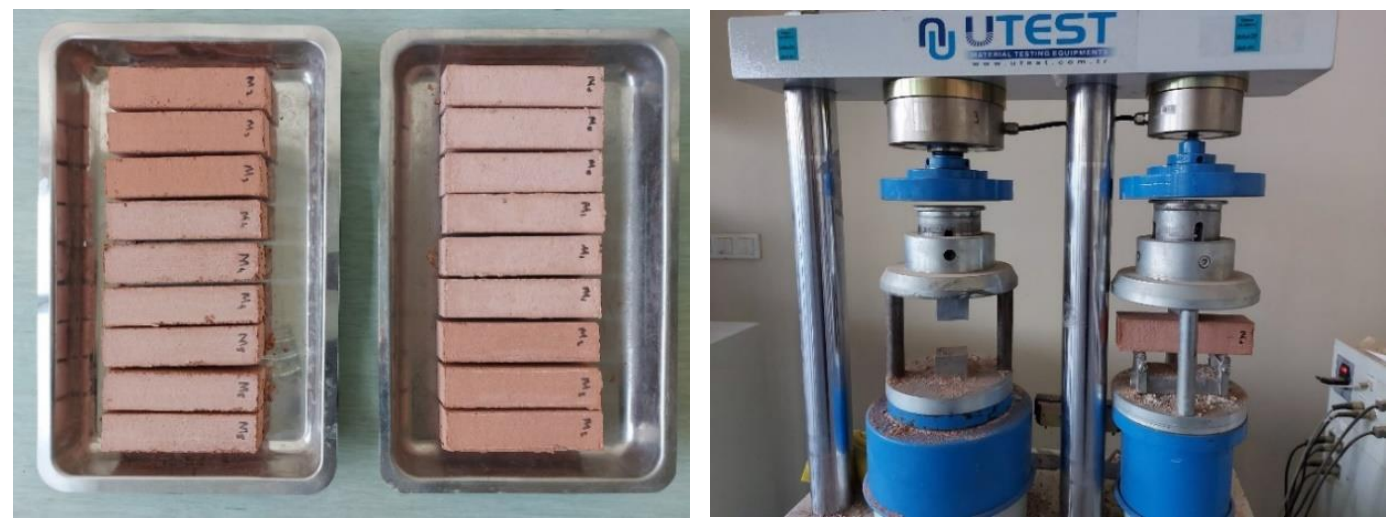

Şekil 3. Horasan harcı örnekleri ve eğilme dayanım deneyi

\section{Bulgular}

Harç örnekleri görsel olarak incelendiğinde, tuğla kırığının harcın rengini etkilediği Şekil 3'te görülmektedir. M2 ve M3 kodlu örneklerin diğerlerine oranla daha koyu renkte olduğu belirlenmiştir. M3 kodlu \% 15 yumurta akı katkılı harç örneklerinin diğerlerine oranla en koyu renkte olduğu tespit edilmiştir.

Horasan harç örnekleri üzerinde yapılan deneylerden elde edilen sonuçlar Tablo 3'te ve grafik halinde Şekil 4, 5, 6 ve 7'de verilmiştir.

Tablo 3. Yayılma, birim hacim ağırlık, ultrases geçiş süresi, eğilme ve basınç dayanımı deney sonuçları

\begin{tabular}{|c|c|c|c|c|c|c|c|}
\hline $\begin{array}{c}\text { Karışım } \\
\text { Kodu }\end{array}$ & $\begin{array}{c}\text { Katk1 } \\
\text { Oran1 } \\
(\%)\end{array}$ & $\begin{array}{c}\text { Yayılma } \\
(\mathrm{mm})\end{array}$ & $\begin{array}{c}\text { Ağırlık } \\
(\mathrm{g})\end{array}$ & $\begin{array}{c}\text { Birim } \\
\text { Hacim } \\
\text { Ağılık } \\
\left(\mathrm{g} / \mathrm{cm}^{3}\right)\end{array}$ & $\begin{array}{c}\text { Ultrases } \\
\text { Geçiş } \\
\text { Süresi } \\
(\mu \mathrm{s})\end{array}$ & $\begin{array}{c}\text { Eğilme } \\
\text { Dayanımı } \\
(\mathrm{MPa})\end{array}$ & $\begin{array}{c}\text { Basınç } \\
\text { Dayanım1 } \\
(\mathrm{MPa})\end{array}$ \\
\hline M0 & 0 & 204 & 443 & 1,73 & 70,3 & 3,6 & 9,1 \\
\hline M1 & 5 & 208 & 421 & 1,65 & 81,5 & 2,8 & 5,2 \\
\hline M2 & 10 & 225 & 383 & 1,49 & 93,4 & 2,4 & 2,9 \\
\hline M3 & 15 & 159 & 373 & 1,46 & 95,6 & 2,2 & 2,4 \\
\hline M4 & 20 & 157 & 336 & 1,31 & 105,1 & 1,9 & 1,2 \\
\hline M5 & 25 & 153 & 322 & 1,26 & 115,2 & 1,3 & 0,8 \\
\hline
\end{tabular}


Araştırma

DOI: $10.34186 /$ klujes. 882789
Kıllç/Kırklareli University Journal of Engineering and Science 7-1(2021) 122-134

Geliş Tarihi:18.02.2021

Taze harçların kıvamını belirlemek amacıyla yayılma tablası ile yapılan deneyler sonucunda M0, M1, M2, M3, M4 ve M5 kodlu harç örneklerinin yayılma miktarları sırasıyla 204, 208, 225, 159, 157 ve 153 mm bulunmuştur. \% 5 ve \%10 yumurta akı katkılı örneklerde yayılma miktarı artmıştır. \% 10 katkılı M2 kodlu karışım örnekleri, \% 10,3 oranında en yüksek artış ile 225 mm yayılma miktarı vermiştir. \% 15, 20 ve 25 katkılı örneklerin, katkısız örneklere oranla yayılma miktarlarında, katkı oranı arttıkça azalma meydana gelmiştir.

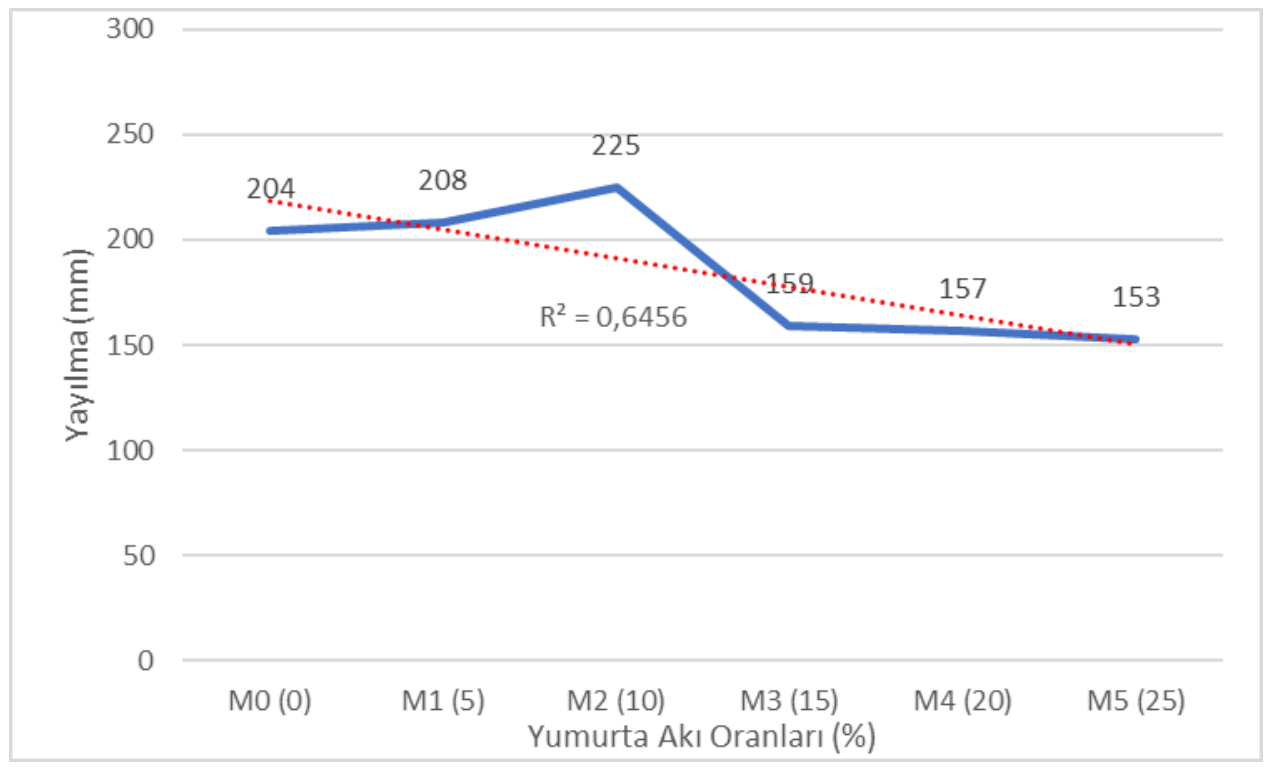

Şekil 4. Horasan harç örneklerinin yayılma miktarları

Karışımlarda, yumurta akı yüzdesinin artmasıyla doğru orantılı olacak şekilde harcın hacminde artış olduğu görülmüştür. Yumurta akı harç içerisinde hava kabarcıkları oluşturarak, boşluklu bir yapı oluşturmuştur. Horasan harcında yumurta akı kullanımının, harcın birim hacim ağırlık değerini katkı miktarıyla ters orantılı olarak düşürdüğü belirlenmiştir. Katkısız M0 harç örneğine oranla yumurta ak1 katkılı M1, M2, M3, M4 ve M5 kodlu harç örneklerinin birim hacim ağırlık değerlerinin sırasıyla \%4, 14, 15, 24 ve 27 oranlarında azaldığı tespit edilmiştir. 
Araştırma

DOI: $10.34186 /$ klujes. 882789
Kıllç/Kırklareli University Journal of Engineering and Science 7-1(2021) 122-134

Geliş Tarihi:18.02.2021

Kabul Tarihi:30.06.2021

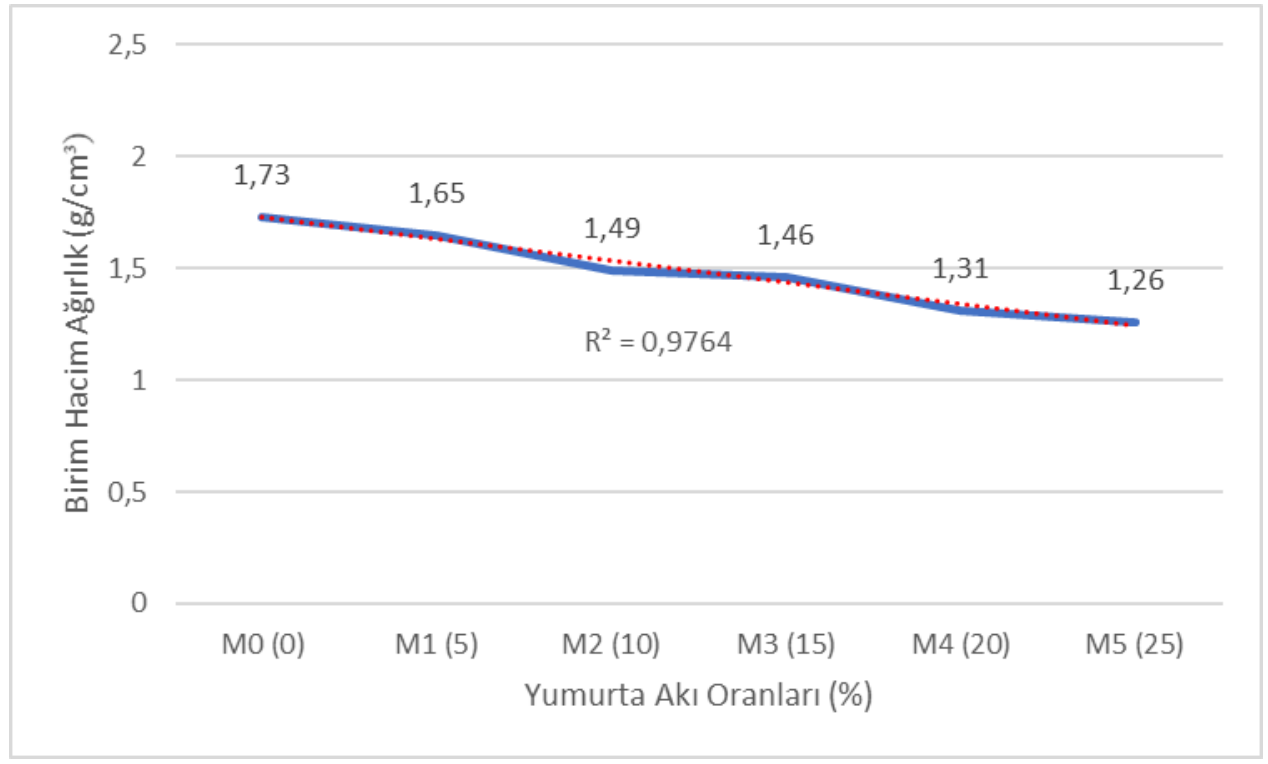

Şekil 5. Horasan harç örneklerinin birim hacim ağırlık değerleri

Oğuz vd. (2015) [18], tarihi eserler üzerinde yapmış oldukları çalışmalarda, birim hacim ağırlık değerlerini Roma dönemi eserlerinde $1,65 \mathrm{~g} / \mathrm{cm}^{3}$, Bizans dönemi eserlerinde $1,57 \mathrm{~g} / \mathrm{cm}^{3}$ ve Selçuklu dönemi eserlerinde ise $1,68 \mathrm{~g} / \mathrm{cm}^{3}$ olarak tespit etmişlerdir. Altaş vd. (2012) [22], tarihi yapılardaki horasan harçlarında görülen birim hacim ağırlı̆̆ın $1,32 \mathrm{~g} / \mathrm{cm}^{3}$ ile 1,61 g/cm ${ }^{3}$ arasında olduğunu belirtmişlerdir. $\mathrm{Bu}$ verilere göre \%5, 10 ve 15 yumurta akı katkılı horasan harç örneklerinden elde edilen birim hacim ağırlık değerlerinin, araştırmacıların belirtmiş olduğu değerlerle uyumlu olduğu görülmüştür.

Ultrases geçiş süreleri incelendiğinde, karışımlardaki yumurta akı oranının artmasıyla doğru orantılı olarak ultrases geçiş sürelerinin de arttı̆̆ı belirlenmiştir. Katkısız M0 harç örneğine oranla M1, M2, M3, M4 ve M5 kodlu katkı1ı harç örneklerinin sırasıyla \%16, 33, 36, 49 ve 64 oranlarında değerlerinin arttığı tespit edilmiştir. Horasan harcında katkı olarak yumurta akı kullanılması, harcın içyapısında boşluklar oluşturmuş ve hacimce genleşmesine neden olmuştur. Boşluklu içyapı oluşumu ise ultrases geçiş süresinin artmasında en önemli etken olmuştur. 
Araştırma

DOI: $10.34186 /$ klujes. 882789

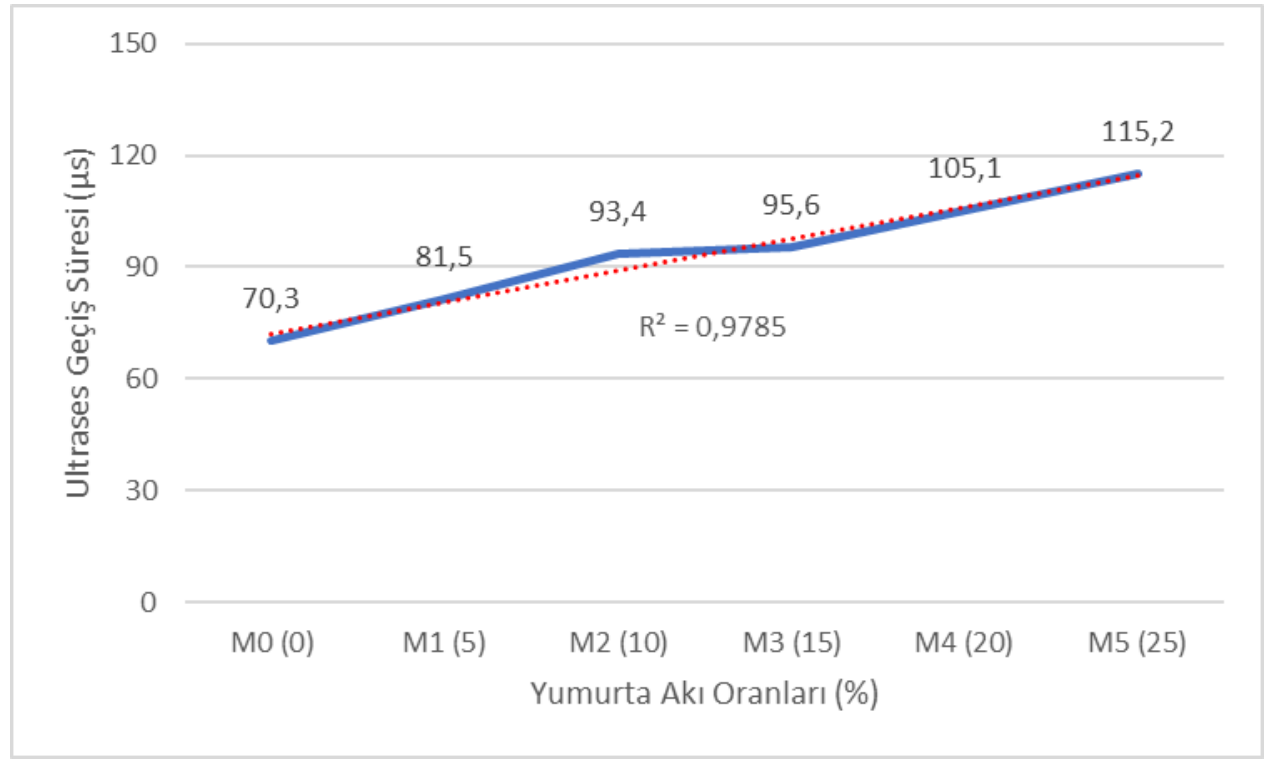

Şekil 6. Horasan harç örneklerinin ultrases geçiş süreleri

Horasan harcında yumurta akı kullanımının eğilme ve basınç dayanımını belirgin bir şekilde azalttı̆̆ı Şekil 7'deki grafiklerde görülmektedir. Katkısız M0 harç örneğine oranla M1, M2, M3, M4 ve M5 kodlu katkılı harç örneklerinin eğilme dayanımı değerlerinde sırasıyla \%22, 33, 39, 47 ve 64 oranlarında, basınç dayanımı değerlerini ise \%43, 68, 73, 87 ve 90 oranlarında azalma tespit edilmiştir. Eğilme ve basınç dayanım değerlerinde, katkı oranının artmasına ters orantılı olacak şekilde azalma meydana gelmiştir. Basınç dayanımının, eğilme dayanımına oranla daha yüksek oranda azaldığı görülmüştür. \%20 ve \%25 yumurta akı katkılı harç örneklerinin, basınç dayanımı eğilme dayanımından daha düşük değerler vermiştir. 


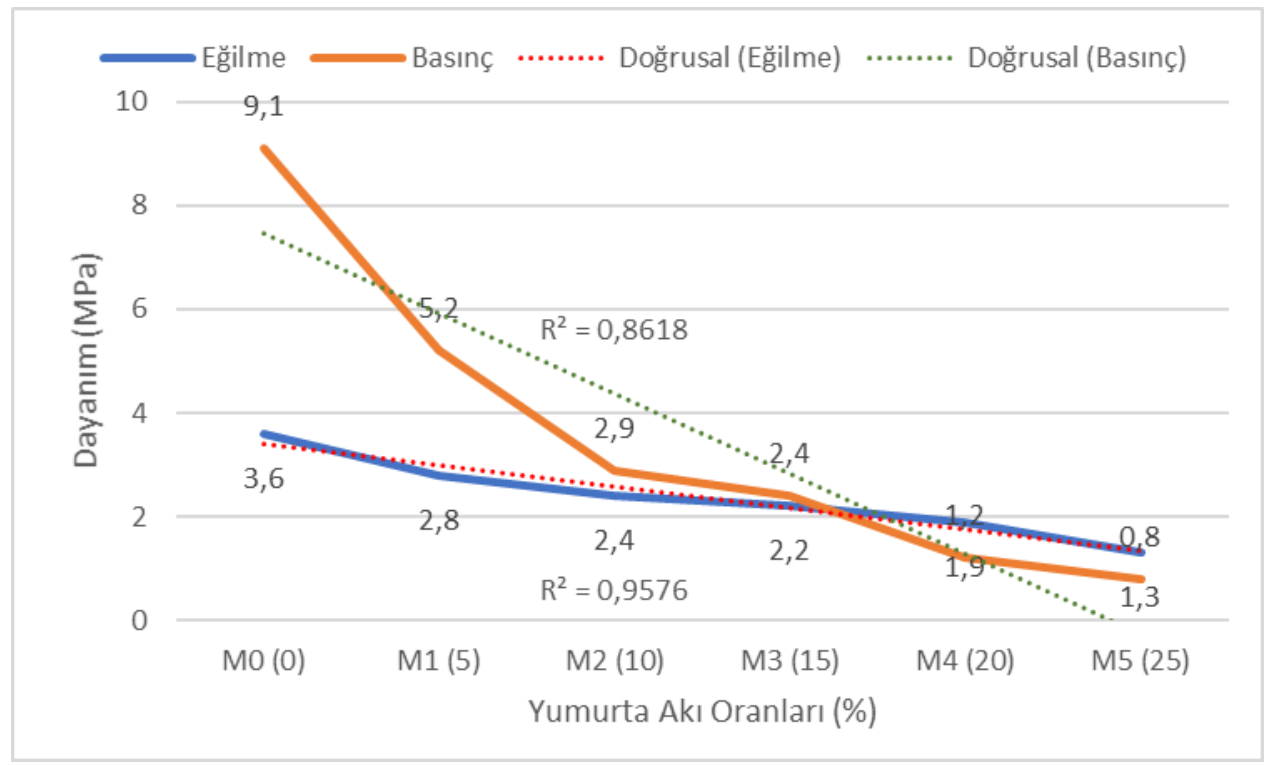

Şekil 7. Horasan harç örneklerinin eğilme ve basınç dayanımı değerleri

Oğuz vd. (2015) [18], tarihi eserler üzerinde yapmış oldukları çalışmalarda, basınç dayanımı değerlerini Roma dönemi eserlerinde $6 \mathrm{MPa}$, Bizans dönemi eserlerinde 8,3 MPa ve Selçuklu dönemi eserlerinde ise 6,6 MPa olarak belirlemişlerdir. Altaş vd. (2012) [22], tarihi yapılardaki horasan harçlarında basınç dayanımı değerinin $6 \mathrm{MPa}$ ile $8 \mathrm{MPa}$ arasında olduğunu belirtmişlerdir. $\mathrm{Bu}$ verilere göre horasan harcında \%5 ve daha fazla oranda yumurta akının katkı olarak kullanılması ile tarihi eserlerdeki harç dayanım değerlerine ulaşılamamıştır. \%5 katkılı horasan harcı örneğinde 5,2 $\mathrm{MPa}$ basınç dayanımı elde edilmiştir. Tarihi eserlerdeki harç dayanım değerlerine ulaşabilmek için yumurta akının \%5'ten daha az oranlarda kullanılması gerektiği tespit edilmiştir. Bu şekilde horasan harcının dayanım değerlerini fazla düşürmeden, yumurta akının olumlu yönlerinden yararlanmak mümkün olabilecektir.

\section{Sonuçlar}

Horasan harcında yumurta akının katkı olarak kullanılmasına yönelik yapılan çalışmada aşağıdaki sonuçlar elde edilmiştir.

- Karışımlarda, \%5 ve \%10 oranlarında yumurta akı kullanılması harçların kıvamını artırmıştır. \%15, 20 ve 25 oranlarında katkı kullanılan harçların kıvamında ise azalma 
Araştırma

DOI: $10.34186 /$ klujes. 882789
Kıllç/Kırklareli University Journal of Engineering and Science 7-1(2021) 122-134

Geliş Tarihi:18.02.2021

meydana gelmiştir. En belirgin azalma \%15 katkı kullanılan M3 kodlu harç örneğinde 159 mm yayılma miktarı ile \%22 oranında olmuştur.

- Yumurta akı, harcın hacimce artışına neden olmuş ve birim hacim ağırlık değerlerini düşürmüştür.

- Harcın içyapısında boşluklar oluşturan yumurta akınının karışımdaki oranının artmasıyla doğru orantılı olarak ultrases geçiş süreleri de artmıştır.

- Yumurta akı kullanılması, eğilme ve basınç dayanımında azalmaya neden olmuştur. Özellikle karışımdaki yumurta akı oranının artmasıyla ters orantılı olarak basınç dayanımında belirgin bir azalma meydana gelmiştir.

Elde edilen bu sonuçlara göre, dayanım açısından yumurta akının horasan harcı karışımlarında \%5'ten fazla kullanılmaması gerekmektedir. Boşluklu bir yapı oluşturmasından dolayı, özellikle sıva harçlarında 1sı ve ses yalıtımı amacıyla kullanılabileceği düşünülmektedir. Ayrıca, yumurta akının horasan harcına katılacak lifli malzemeler ile harç arasında ki aderansa ne yönde etkilerinin olabileceği araştırılmalıdır.

\section{Kaynaklar}

[1] İpekoğlu B., Böke H., and Çizer Ö., Assessment of Material Use in Relation to Climate in Historical Buildings. Building and Environment, 42(2), 970-978, 2007. Doi:10.1016/j.buildenv.2005.10.029

[2] Uğurlu E., Böke H., The Use of Brick-Lime Plasters and Their Relevance to Climatic Conditions of Historic Bath Buildings. Construction and Building Materials 23(6):2442-2450, 2009. Doi:10.1016/j.conbuildmat.2008.10.005

[3] Topçu İ. B., Canbaz M., Karanfil H., Horasan Harç ve Betonun Özellikleri, Yapı Mekaniği Semineri, ODTÜ-ESOGÜ, 99-107, Eskişehir, 2005.

[4] Özkaya Ö.A., Böke H., Properties of Roman Bricks and Mortars Used in Serapis Temple in The City of Pergamon, Materials Characterization, 60(9), 995-1000, 2009. Doi:10.1016/j.matchar.2009.04.003

[5] Prince W., Castanier G., Giafferi J.L., Similarity Between Alkali-Aggregate Reaction and The Natural Alternation of Rocks, Cement and Concrete Research, 31(2), 271-276, 2001. Doi:10.1016/S0008-8846(00)00478-6 
[6] Mavioğlu Ü.A., Farklı Puzolanik Katkıllar ile Hazırlanan Horasan Harçlarının Değişen Parametrelerinin İncelenmesi, Yüksek Lisans Tezi, İstanbul Teknik Üniversitesi Fen Bilimleri Enstitüsü, İstanbul, 2011.

[7] Fang S., Zhang H., Zhang B., and Zheng Y., The Identification of Organic Additives in Traditional Lime Mortar, Journal of Cultural Heritage, 15(2), 144-150, 2014. Doi:10.1016/j.culher.2013.04.001

[8] Ventola L., Vendrell M., Giraldez P., and Merino L., Traditional Organic Additives Improve Lime Mortars: New Old Materials for Restoration and Building Natural Stone Fabrics, Construction and Building Materials, $25 \quad$ (8), 3313-3318, 2011. Doi:10.1016/j.conbuildmat.2011.03.020

[9] Altun M.G., Özen S., Aghabaglou, A.M., Polipropilen Lif Kullanımının Doğal Hidrolik Kireçli Harçların Kuruma Büzülmesine Etkisi, Sakarya Üniversitesi Fen Bilimleri Enstitüsü Dergisi, 22 (2), 427-435, 2018. Doi: 10.16984/saufenbilder.342521

[10] Böke H., Akkurt S., İpekoğlu B., Tarihi Yapılarda Kullanılan Horasan Harcı ve Sıvalarının Özellikleri, Yap1 Dergisi, 269, 90-95, 2004.

[11] Dariz P., Schmid T., Ferruginous Phases in 19th Century Lime and Cement Mortars: A Raman Microspectroscopic Study, Materials Characterization, 129, 9-17, 2017. Doi: 10.1016/j.matchar.2017.04.009

[12] Seabra M., Paiva H., Labrincha J. and Ferreira V., Admixtures Effect on Fresh State Properties of Aerial Lime Based Mortars, Construction and Building Materials, 23(2), 1147-1153, 2009. Doi: 10.1016/j.conbuildmat.2008.06.008

[13] Güleç A., Tulun T. Physico-Chemical and Petrographical Studies af Old Mortars and Plasters of Anatolia, Cement and Concrete Research, 27(2), 227-234, 1997. Doi:10.1016/S00088846(97)00005-7

[14] Böke H., Akkurt S., Ettringite Formation in Historic Bath Brick-Lime Plasters. Cement and Concrete Research, 33(9), 1457-1464, 2003. Doi:10.1016/S0008-8846(03)00094-2

[15] Stefanidou, M., Pachta, V., Konopissi, S., Karkadelidou, F., Papayianni, I., Analysis and Characterization of Hydraulic Mortars from Encient Cisterns and Baths in Greece, Materials and Structures, 47(4), 571-580, 2014.

[16] Matias, G., Faria, P., Torres I., Lime Mortars with Heat Treated Clays and Ceramic Waste: A Review, Construction and Building Materials, 73, 125-136, 2014. Doi: 10.1016/j.conbuildmat.2014.09.028 
DOI: $10.34186 /$ klujes. 882789
Kıllıç/Kırklareli University Journal of Engineering and Science 7-1(2021) 122-134

Geliş Tarihi:18.02.2021

[17] Nezerka, V., Nemecek, J., Slizkova, Z., Tesarek, P., Investigation of Crushed Brick-Matrix Interface in Lime-Based Ancient Mortar by Microscopy and Nanoindentation, Cement and Concrete Composites, 55, 122-128, 2015. Doi: 10.1016/j.cemconcomp.2014.07.023

[18] Oğuz C., Türker F., Koçkal N.U., Andriake Limanı'nda Roma, Bizans ve Selçuklu Dönemi Harçların Özellikleri, İMO Teknik Dergi, 429, 6993-7013, 2015.

[19] Tosun Y., Oltulu M., Polat R., Şahin R., Bingöl, A.F., Hidrolik Kireçli Harçlarda Uçucu Kül Kullanımı, 5. Tarihi Eserlerin Güçlendirilmesi ve Geleceğe Güvenle Devredilmesi Sempozyumu, Cilt 1, 103-112, 2015.

[20] Özgen Ö., Horasan Harcı Üzerine Deneysel Çalışmalar, T.C. Kültür ve Turizm Bakanlığı İstanbul Rölöve ve Anıtlar Müdürlüğü, Uzmanlık Tezi, İstanbul, 2002.

[21] Gürdal E., Altaş G.K., Özgünler S.A., İstanbul'da Bulunan Erken Bizans Dönemi Dini Yapılarında Kullanılan Horasan Harçlarının Özelliklerinin İncelenmesi, Vakıf Restorasyon Yıllığı, 2, 2012.

[22] Altaş G.K., Özgünler S.A., Güldal E., İstanbul'daki Roma Dönemi Saray Yapılarındaki Horasan Harçlarının İncelenmesi, Vakıf Restorasyon Yı1lığı, 4, 2012.

[23] Canbaz M., Güler E., Kireç Türünün Horasan Harcı Özelliklerine Etkisi, 6. Tarihi Yapıların Korunması ve Güçlendirilmesi Sempozyumu, 2017.

[24] Cinemre M., Kesme Taş Duvarlarda Kullanılan Tarihi Horasan Harçlarının Mekanik Özelliklerinin İncelenmesi, Yüksek Lisans Tezi, Sakarya Uygulamalı Bilimler Üniversitesi Lisansüstü Eğitim Enstitüsü, Sakarya, 2019.

[25] TS EN 1015-3, Kagir Harc1-Deney Metotları-Bölüm3: Taze Harç Kıvamının Tayini (Yayılma Tablası ile), TSE, Ankara, 2000.

[26] TS EN 1015-11, Kagir Harcı-Deney Yöntemleri-Bölüm11: Sertleşmiş Harcın Eğilmede Çekme ve Basınç Dayanımının Tayini, TSE, Ankara, 2020.

[27] ASTM C 597, Standard Test Method for Pulse Velocity Through Concete, American Society for Testing and Materials, ASTM International, USA, 2002. 